\title{
SCHMERZGEDÄCHTNIS
}

\section{Sagen Sie nicht „das piekst jetzt ein bisschen“!}

Es ist sicher gut gemeint, wenn der Doktor vor einer Injektion sagt: „Das piekst jetzt ein bisschen“. Die Wirkung dieser Worte kann aber sehr nachhaltig sein, haben Psychologen der Universität Jena mithilfe der funktionellen MRT herausgefunden. Demnach können die Worte allein schon das Schmerzzentrum im Gehirn aktivieren. Sensible Patienten spüren dann möglicherweise den
Injektionsschmerz bereits, während sie noch im Wartezimmer sitzen. Und das gilt keineswegs nur für Kinder. Daher wäre es vielleicht besser, gar nicht über mögliche Schmerzsensationen zu reden, wenn Sie einem $\mathrm{Pa}$ tienten eine Spritze verabreichen. Ohne Triggerworte, die Schmerzempfindungen auslösen, tut die nächste Spritze vielleicht nur halb so weh. Pain 2010;148(2):198-205

\section{OSTER-FEIERTAGE}

\section{Haben Sie auch was für Ihren Blutdruck getan?}

Die gute Nachricht für alle, die an Ostern zu viel Schokolade gegessen haben: Die Schokoeier und -hasen können den Blutdruck senken und so kardiovaskuläre Ereignisse verhindern. In einer deutschen Beobachtungsstudie mit 19350 Personen hatten diejenigen mit dem höchsten Schokoladenverbrauch einen um 1,0/0,9

\section{FOLGE DER IMPFVERWEIGERUNG}

\section{Anstieg bei Orchitisfällen}

Britische Urologen berichten über eine alarmierende Zunahme von Mumps-Orchitis bei jungen Männern. Zurückgeführt wird er auf den starken Rückgang bei MMR-Impfungen in Großbritannien Mitte der 1990er-Jahre. Damals hatten (inzwischen widerlegte) Spekulationen über einen Zusammenhang zwischen Impfung und Autismus sowie chronisch entzündlichen Darmerkrankungen den Impfgegnern Munition geliefert.

BJU Internat 2010;105(8):1060-1065
$\mathrm{mmHg}$ niedrigeren Blutdruck und gut ein Drittel weniger Herzinfarkte und Schlaganfälle als Personen, die fast keine Schokolade aßen. Die Sache hat allerdings einen Haken: In der Gruppe mit dem höchsten Schokoladenkonsum wurden gerade mal 7,5 g pro Tag verspeist.

Eur Heart J 2010; doi: 10.1093/eurheartj/ehq068

\section{Geschichten aus der Praxis}

Eine Patientin meint, an ihrer Gürtelrose seien „verdreckte“ EKG-Elektroden schuld. Eine andere opfert ihre Gesundheit, um den Traum vom Eigenheim zu verwirklichen. Von diesen Praxiserlebnissen erzählen MMW-Leser auf S. 24. Wenn Sie auch Anekdoten aus Ihrem Praxisalltag auf Lager haben, schreiben Sie an Brigitte.Moreano@ springer.com. Jeder veröffentlichte Text wird honoriert.

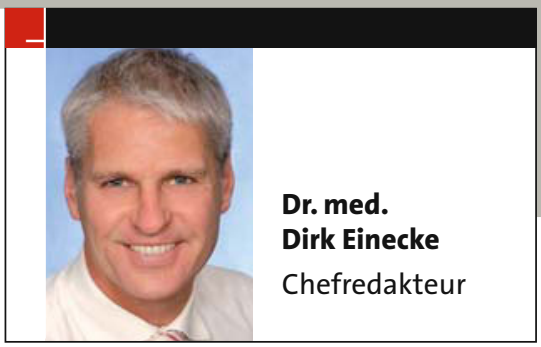

\section{COMPLIANCE}

\section{Vorsicht, die Pille petzt}

Non-Compliance kann das Ergebnis klinischer Studien erheblich verfälschen. In manchen Studien müssen die Studienteilnehmer das Versuchspräparat deswegen unter ärztlicher Aufsicht einnehmen. Bei großen Studien ist dies jedoch kaum praktikabel.

An der Universität Florida wird derzeit eine Tablettenkapsel entwickelt, die über einen Mikrochip ein Signal abgibt, sobald sie geschluckt wird, eine petzende Pille sozusagen. Die Kapsel soll nicht nur für Studien Verwendung finden, sondern beispielsweise auch bei alten Patienten, die die Tabletteneinnahme oft vergessen. Handelt es sich um ein lebenswichtiges Medikament, können der Arzt oder die Angehörigen des Patienten mithilfe des Pillensignals die Einnahme kontrollieren.

Pressemitteilung der University of Florida

\section{KOGNITIVER ABBAU}

\section{Erhöhtes CRP mindert Urteilskraft}

Patienten mit erhöhten Werten des C-reaktiven Proteins (CRP) schneiden in neuropsychiatrischen Tests schlechter ab als Probanden mit niedrigeren Werten. Beeinträchtigt sind besonders die exekutiven Funktionen, d. h. die Fähigkeit zum vernünftigen, planerischen Denken. Zudem wurden bei Patienten mit erhöhtem CRP mittels MRT Veränderungen in den Frontallappenbereichen nachgewiesen, die für die exekutiven Fähigkeiten zuständig sind.

Neurology 2010;74:1022-1029 